\title{
Natural convection of ferrofluid from a fixed vertical plate with aligned magnetic field and convective boundary condition
}

\author{
Mohd Rijal llias a, b, Noraihan Afiqah Rawi ${ }^{b}$, Sharidan Shafie ${ }^{b, *}$ \\ a Department of Mathematical Sciences, Faculty of Computer and Mathematical Sciences, UiTM Shah Alam, 40450 Shah Alam, Selangor, \\ Malaysia \\ b Department of Mathematical Sciences, Faculty of Science, Universiti Teknologi Malaysia, 81310 UTM Johor Bahru, Johor, Malaysia \\ * Corresponding author: sharidan@utm.my
}

\section{Article history}

Received 8 March 2017

Accepted 4 July 2017

\begin{abstract}
The present study analyzed the influence of aligned and transverse magnetic field on two dimensional natural convection boundary layer flow of a ferrofluid over a fixed vertical plate in the presence of convective boundary condition. It is assumed that the left surface of the plate is in contact with a hot fluid while the cold fluid on the right surface. Two different base fluids (water and kerosene) containing magnetite $\left(\mathrm{Fe}_{3} \mathrm{O}_{4}\right)$ as ferroparticle are considered. The governing boundary layer equations along with the appropriate boundary conditions are transformed to a set of ordinary differential equations using similarity variables. The resultant system of equations is then solved numerically by using Keller-Box method. Numerical results for the skin friction coefficient and local Nusselt number were presented whilst the velocity and temperature profiles illustrated graphically and analyzed. The effect of the inclined angle, magnetic field parameter, volume fraction, Grashof number and Biot number on the flow field were discussed. It is found that the heat transfer rate at the plate surface with $\mathrm{Fe}_{3} \mathrm{O}_{4}-$ kerosene ferrofluid is higher than $\mathrm{Fe}_{3} \mathrm{O}_{4}$-water.
\end{abstract}

Keywords: Free convection, MHD, ferrofluid, vertical flat plate, convective boundary condition

\section{INTRODUCTION}

Nanofluid is a suspension containing a certain quantity of nanoscaled solid particles in a conventional cooling liquid, such as water, kerosene and ethylene glycol [1]. Nanofluid shows considerably better heat transfer performance than single-phase mediums due to particle's Brownian motion and interaction [2,3]. Furthermore, because of the ultra-small particle size, nanofluid is also remarkably better than normal multi-phase fluid to eliminate erosion and clogging problems in micro channels $[4,5]$. Magnetic nanofluid called as ferrofluid is a colloidal mixture of base liquid and magnetic nanoparticles of size between 10-20 nm.

Magnetohydrodynamic (MHD) thermal boundary layer continues to receive considerable attention due to its numerous applications such as polymer extrusion, cooling of electronic devices and nuclear reactors, enhanced oil recovery and the design of heat exchangers. Blasius [6] who presented a theoretical result for the boundary layer flow over a flat plate in a uniform stream and on a circular cylinder. After that, a lot of researchers have further investigate and extended his work by introducing various parameters that can give the effect to the practical applications.Makinde and Olanrewaju [7] investigated the effects of buoyancy forces on thermal boundary layer over a flat plate with a convective boundary condition.Aziz [8] presented similarity solution for laminar thermal boundary layer over a flat plate with a convective surface boundary condition.

Recently, nanofluid is increasingly used in natural convection applications for wide areas [9]. To gain a better understanding of nanofluid natural heat convection, many studies have been carried out in both experimental and numerical ways during the past decade [1012]. Makinde [13] presented similarity solution for natural convection from a moving vertical plate with internal heat generation and a convective boundary condition whilst Olanrewaju et al., [14] investigated the effects of internal heat generation on thermal boundary layer with a convective surface boundary condition. Their results revealed that an increase in the internal heat generation prevents the rapid flow of heat from the lower surface to the upper surface of the plate.

This paper investigates the effect of aligned and transverse magnetic field on MHD thermal boundary layer flow over a fixed vertical flat plate with convective boundary condition.

\section{PROBLEM FORMULATION}

Consider a steady laminar two dimensional boundary layer flow with heat transfer along a fixed vertical flat plate in a stream of water and kerosene based ferrofluid containing magnetite $\left(\mathrm{Fe}_{3} \mathrm{O}_{4}\right)$ as ferroparticle. The left surface of the plate is heated by convection from a hot fluid at temperature $T_{f}$ which provides a heat coefficient $h_{f}$. The physical model is presented in Fig. 1. In all these studies, the ferrofluid is assumed incompressible and the viscous dissipation and radiation effects are neglected. It is also assumed that the base fluids and the suspended ferroparticle are in thermal equilibrium and no slip occurs between them. Under the Boussinesq for fluid density variation, the continuity, momentum and energy equations describing the flow can be written as [15] combined with the mathematical nanofluid model given by Tiwari and Das [16]:

$$
\frac{\partial u}{\partial x}+\frac{\partial v}{\partial y}=0
$$




$$
\begin{gathered}
u \frac{\partial u}{\partial x}+v \frac{\partial u}{\partial y}=\frac{\mu_{n f}}{\rho_{n f}} \frac{\partial^{2} u}{\partial y^{2}}+\frac{(\rho \beta)_{n f}}{\rho_{n f}} g\left(T-T_{\infty}\right) \\
-\frac{\sigma B_{O}^{2}}{\rho_{n f}} \sin ^{2} \alpha\left(u-U_{\infty}\right) \\
u \frac{\partial T}{\partial x}+v \frac{\partial T}{\partial y}=\alpha_{n f} \frac{\partial^{2} T}{\partial y^{2}}
\end{gathered}
$$

along with boundary conditions

$$
\begin{array}{ll}
u(x, 0)=0, \quad v(x, 0)=0, & -k_{f} \frac{\partial T(x, 0)}{\partial y}=h_{f}\left[T_{f}-T(x, 0)\right] \\
u(x, \infty)=U_{\infty}, & T(x, \infty)=T_{\infty}
\end{array}
$$

where $u$ and $v$ are the $x$ (along the plate) and the $y$ (normal to the plate) component of velocities, respectively, $\alpha$ is the inclined angle, $T$ is the temperature of the ferrofluid, $T_{\infty}$ is the free stream temperature, $g$ is the gravity acceleration, $B_{o}$ is strength of magnetic field, $U_{\infty}$ is the constant free stream velocity, $\sigma$ is the electrical conductivity, $\rho_{n f}$ is the effective density, $\mu_{n f}$ is the effective dynamic viscosity, $(\rho \beta)_{n f}$ is the thermal expansion coefficient and $\alpha_{n f}$ is the thermal diffusitivity of the ferrofluid, which is given as [17]

$$
\begin{gathered}
\rho_{n f}=(1-\phi) \rho_{f}+\phi \rho_{s}, \mu_{n f}=\frac{\mu_{f}}{(1-\phi)^{2.5}} \\
(\rho \beta)_{n f}=(1-\phi)(\rho \beta)_{f}+\phi(\rho \beta)_{s}, \alpha{ }_{n f}=\frac{k_{n f}}{\left(\rho C_{p}\right)_{n f}} .
\end{gathered}
$$

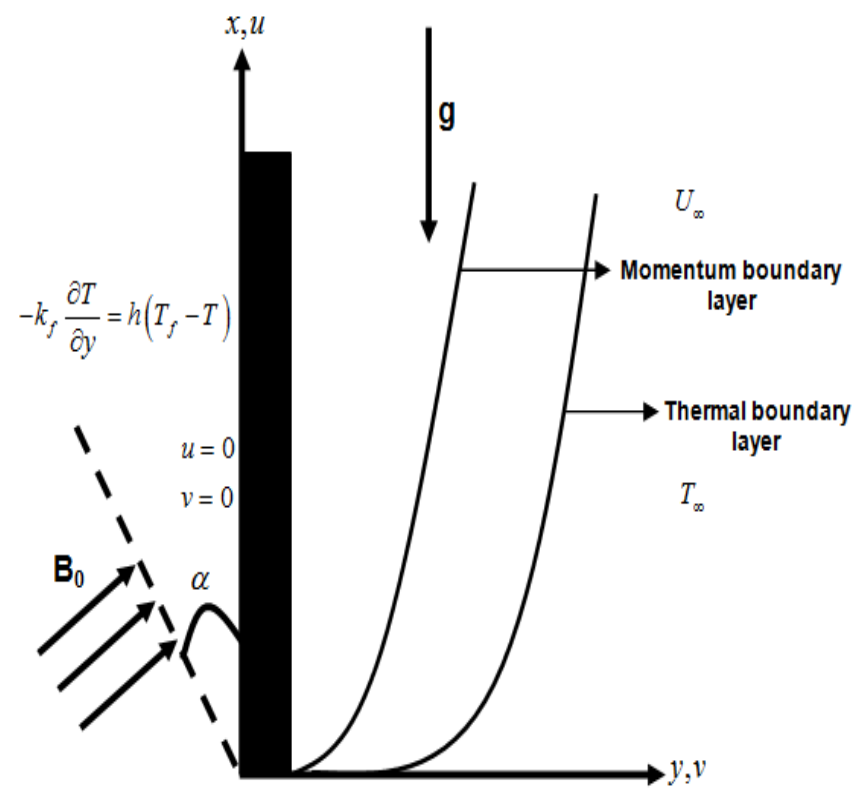

Fig. 1 Physical model and coordinate system.

Here, $\phi$ is the solid volume fraction, $\mu_{f}$ is the dynamic viscosity of the base fluid, $\rho_{f}$ and $\rho_{s}$ are the densities of pure fluid and nanoparticles, respectively, $\left(\rho C_{p}\right)_{n f}$ is the heat capacity of the ferrofluid and $k_{n f}$ is the thermal conductivity of the ferrofluid given by

$$
\begin{gathered}
\left(\rho C_{p}\right)_{n f}=(1-\phi)\left(\rho C_{p}\right)_{f}+\phi\left(\rho C_{p}\right)_{s}, \\
\frac{k_{n f}}{k_{f}}=\frac{k_{s}+2 k_{f}-2 \phi\left(k_{f}-k_{s}\right)}{k_{s}+2 k_{f}+\phi\left(k_{f}-k_{s}\right)}
\end{gathered}
$$

where $\left(\rho C_{p}\right)_{f}$ and $\left(\rho C_{p}\right)_{s}$ are the specific heat parameters of the base fluid and nanoparticles and $k_{f}$ and $k_{s}$ are thermal conductivities of the ferrofluid and ferroparticles. The viscosity of the ferrofluid $\mu_{n f}$ can be approximated as the viscosity of a base fluid $\mu_{f}$ containing dilute suspension of fine spherical particles and is given by Brikmann[18]. The effective thermal conductivity of the ferrofluid $k_{n f}$ is approximated by Maxwell-Garnett's model, which is found to be appropriate for studying heat transfer enhancement using ferrofluids. The stream function $\psi$, satisfies the continuity Eq. (1) automatically.

$$
u=\frac{\partial \psi}{\partial y} \text { and } v=-\frac{\partial \psi}{\partial x}
$$

A similarity solution of Eqs. (1) - (3) along with boundary conditions (4) is obtained by defining variable $\eta$ and a dependent variable $f$ in term of the stream function $\psi$ :

$$
\eta=y \sqrt{\frac{U_{\infty}}{v_{f} x}}=\frac{y}{x} \sqrt{\operatorname{Re}_{x}}, \psi=v_{f} \sqrt{\operatorname{Re}_{x}} f(\eta), \theta=\frac{T-T_{\infty}}{T_{w}-T_{\infty}}
$$

where $\operatorname{Re}_{x}=\frac{U_{\infty} x}{v_{f}}$ is the Reynolds number.

Employing the similarity variables (7) and (8), (1) - (3) reduce to the following nonlinear system of ordinary differential equations:

$$
\begin{aligned}
& f^{\prime \prime \prime}+(1-\phi)^{2.5}\left(1-\phi+\phi\left(\frac{\rho_{s}}{\rho_{f}}\right)\right) \frac{1}{2} f f^{\prime \prime} \\
& +(1-\phi)^{2.5}\left(1-\phi+\phi\left(\frac{(\rho \beta)_{s}}{(\rho \beta)_{f}}\right)\right) G r_{x} \theta \\
& +(1-\phi)^{2.5} M(1-f) \sin ^{2} \alpha=0 \\
& \left(\frac{k_{n f}}{k_{f}}\right) \theta^{\prime \prime}+\frac{\operatorname{Pr}}{2}\left(1-\phi+\phi \frac{\left(\rho C_{p}\right)_{s}}{\left(\rho C_{p}\right)_{f}}\right) f \theta^{\prime}=0
\end{aligned}
$$

subjected to the boundary conditions (5) which become

$$
\begin{aligned}
& f(0)=0, \quad f^{\prime}(0)=0, \quad \theta^{\prime}(0)=-B i_{x}(1-\theta(0)) \\
& f^{\prime}(\eta)=1, \quad \theta(\eta)=0, \quad \text { as } \eta \rightarrow \infty
\end{aligned}
$$

where primes denote differentiation with respect to $\eta$ $\operatorname{Pr}=\left(\mu C_{p}\right)_{f} / k_{f}$ is the Prantl number, $M=\sigma B_{0}^{2} / \rho U_{\infty}$ is the magnetic parameter, $G r_{x}=g \beta_{f}\left(T_{w}-T_{\infty}\right) x / U_{\infty}^{2}$ is the local Grashof number and $B i_{x}=\frac{h_{f}}{k} \sqrt{\frac{v_{f} x}{U_{\infty}}}$ is the local Biot Number. In order to have 
a true similarity solution, the parameter $G r_{x}$ and $B i_{x}$ must be constant and independent of $x$. This condition will be satisfied if the thermal expansion coefficient $\beta_{f}$ proportional to $x^{-1}$ and $h_{f}$ is proportional to $x^{-\frac{1}{2}}$ Hence, assume[13],

$$
\beta_{f}=a x^{-1}, h_{f}=c x^{-\frac{1}{2}}
$$

where $a$ and $c$ are constant but have the appropriate dimension. Substituting (12) into the parameter $G r_{x}$ and $B i_{x}$,

$$
G r=\frac{a g\left(T_{w}-T_{\infty}\right)}{U_{\infty}^{2}}, B i=\frac{c}{k} \sqrt{\frac{v_{f}}{U_{\infty}}} .
$$

Quantities of practical interest, in this study, are the skin-friction coefficient, $C_{f}$ at the surface of the plate and local Nusselt number, $N u_{x}$ which are defined as:

$$
C_{f}=\frac{\tau_{w}}{\rho_{f} U_{\infty}^{2}}, \quad N u_{x}=\frac{x q_{w}}{k_{f}\left(T_{f}-T_{\infty}\right)}
$$

where $\tau_{w}$ is the wall skin friction or shear stress at the plate and $q_{w}$ is the heat flux from the plate, which given by:

$$
\tau_{w}=\mu_{n f}\left(\frac{\partial u}{\partial y}\right)_{y=0}, \quad q_{w}=-k_{n f}\left(\frac{\partial T}{\partial y}\right)_{y=0}
$$

Substituiting (8) into (15) and using (14),

$$
\frac{C_{f}}{\left(\operatorname{Re}_{x}\right)^{\frac{1}{2}}}=\frac{1}{(1-\phi)^{2.5}} f^{\prime \prime}(0), \frac{N u_{x}}{\left(\operatorname{Re}_{x}\right)^{-\frac{1}{2}}}=-\frac{k_{n f}}{k_{f}} \theta^{\prime}(0)
$$

\section{RESULTS AND DISCUSSION}

The above set of Eqs. (9) - (10) subject to the boundary conditions (11) were solved numerically by using Keller Box method. Both velocity and temperature profiles were obtained and utilized to compute the skin friction coefficient and the local Nusselt number in (16). Two types of base fluids containing ferroparticle of $\mathrm{Fe}_{3} \mathrm{O}_{4}$ is considered. The thermophysical properties of water, kerosene and $\mathrm{Fe}_{3} \mathrm{O}_{4}$ are taken from Table 1.

The values of Prandtl number number for the base fluids, water and kerosene are taken to be 6.2 and 21 , respectively. The effect of the volume fraction of solid ferroparticle $\phi$ is studied in the range $0 \leq \phi \leq 0.2$, where $\phi=0$ represents the pure fluid water or kerosene. The results of the present investigation were compared with those of the studies available in literature and found to be in good agreement (Table 2).

Table 1 Thermophysical properties of base fluids and ferroparticle $[19,20]$.

\begin{tabular}{cccc}
\hline Physical Properties & Water & Kerosene & $\mathrm{Fe}_{3} \mathrm{O}_{4}$ \\
\hline$\rho\left(\mathrm{kg} / \mathrm{m}^{3}\right)$ & 997.1 & 780 & 5200 \\
$C_{p}(\mathrm{~J} / \mathrm{kgK})$ & 4179 & 2090 & 670 \\
$k(\mathrm{~W} / \mathrm{mK})$ & 0.613 & 0.149 & 6 \\
$\beta \times 10^{-5}\left(K^{-1}\right)$ & 21 & 99 & 1.3 \\
\hline
\end{tabular}

Table 2 Comparison of the skin friction coefficient for different values of volume fraction of ferroparticle.

\begin{tabular}{cccc}
\hline & \multicolumn{2}{c}{$G r_{x}=0, \alpha=90^{\circ}$} \\
& $\begin{array}{c}\text { Volume } \\
\text { Fraction }\end{array}$ & $\begin{array}{c}\text { Khan et } \\
\text { al.[14] }\end{array}$ & $\begin{array}{c}\text { Present } \\
\text { Study }\end{array}$ \\
\hline $\mathrm{Fe}_{3} \mathrm{O}_{4}$-water & 0.01 & 0.34324 & 0.343238 \\
& 0.1 & 0.45131 & 0.451324 \\
$\mathrm{Fe}_{3} \mathrm{O}_{4}$-kerosene & 0.2 & 0.59517 & 0.595192 \\
& 0.01 & 0.34557 & 0.345569 \\
& 0.1 & 0.47336 & 0.473360 \\
& 0.2 & 0.63950 & 0.639499 \\
\hline
\end{tabular}

In order to bring out the salient features of the flow and the heat transfer characteristics, the numerical values for different values of the governing parameters $\alpha, \phi, M, G r_{x}$ and $B i_{x}$ are portrayed in Figs. $1-$ 10. Figs. 2 and 3 show the effect of inclined magnetic field on velocity and temperature profiles. It can be observed that, an increase in the aligned angle enhances the velocity profiles and depreciates the temperature profiles for both ferrofluids. At $\alpha=\pi / 2$, this aligned magnetic field acts like transverse magnetic field and ferroparticles are attracted by the magnetic field. In Fig. 4 and 5, the effect of increasing the magnetic field strength on the momentum and thermal boundary layer thickness is illustrated. Generally, increase in magnetic field arranges the ferroparticles in order. Due to this reasons, it can be seen an increase velocity profiles of the flow.

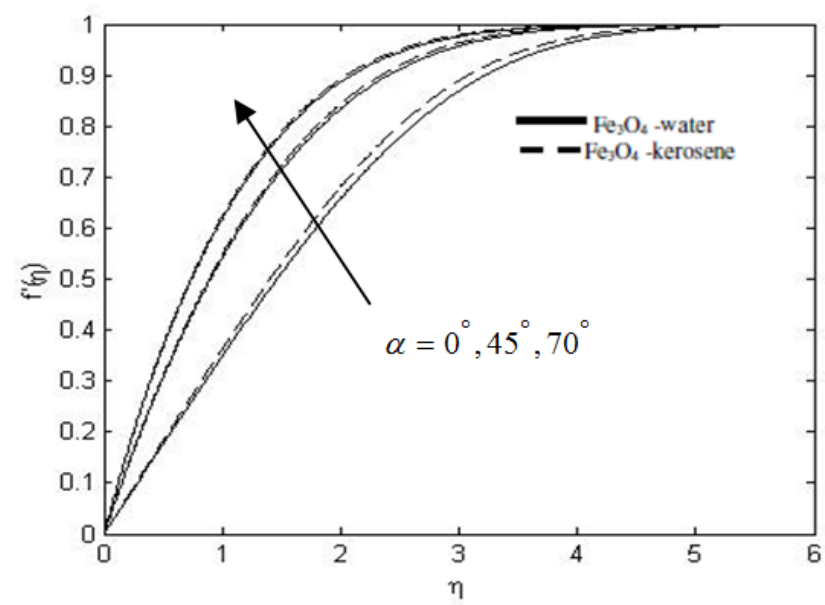

Fig. 2 Velocity Profile for increasing of inclined angle, $\alpha$ for $M=1, \phi=0.1, G r_{x}=0.1, B i_{x}=0.1$.

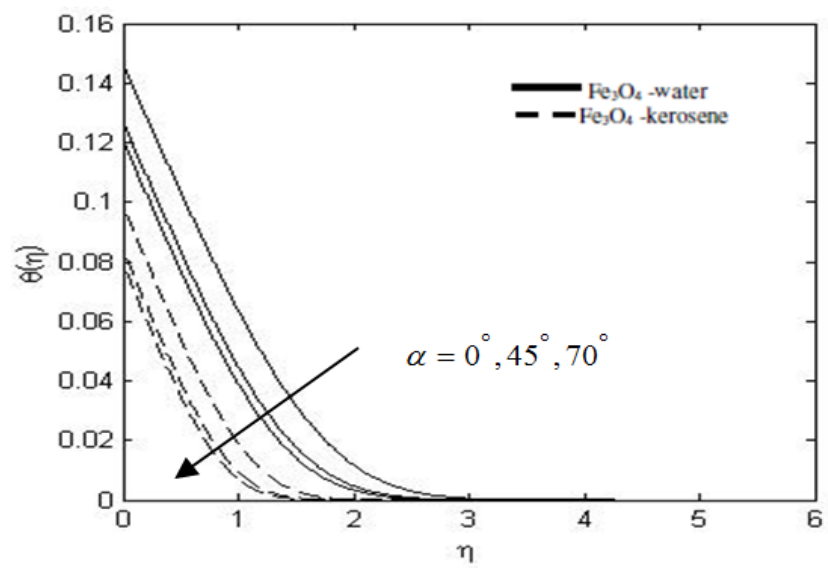

Fig. 3 Temperature Profile for increasing of inclined angle, $\alpha$ for $M=1, \phi=0.1, G r_{x}=0.1, B i_{x}=0.1$ 


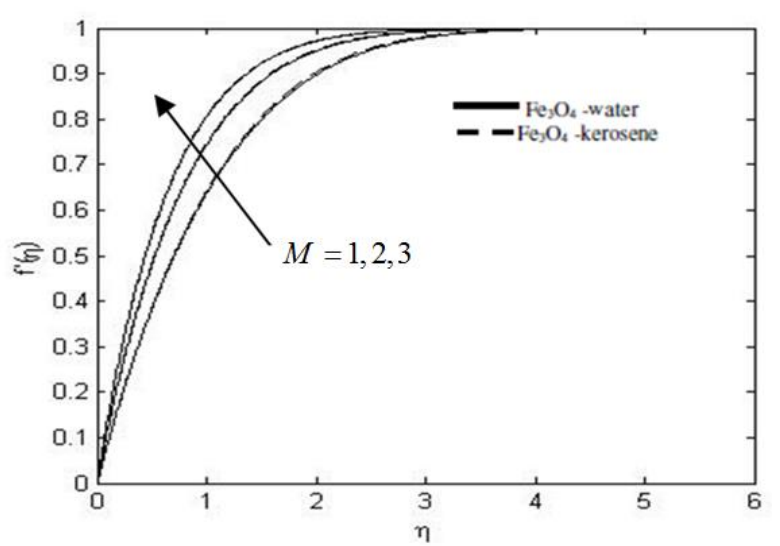

Fig. 4 Velocity Profile for increasing of Magnetic Field, $M$ for $\alpha=\pi / 2, \phi=0.1, G r_{x}=0.1, B i_{x}=0.1$.

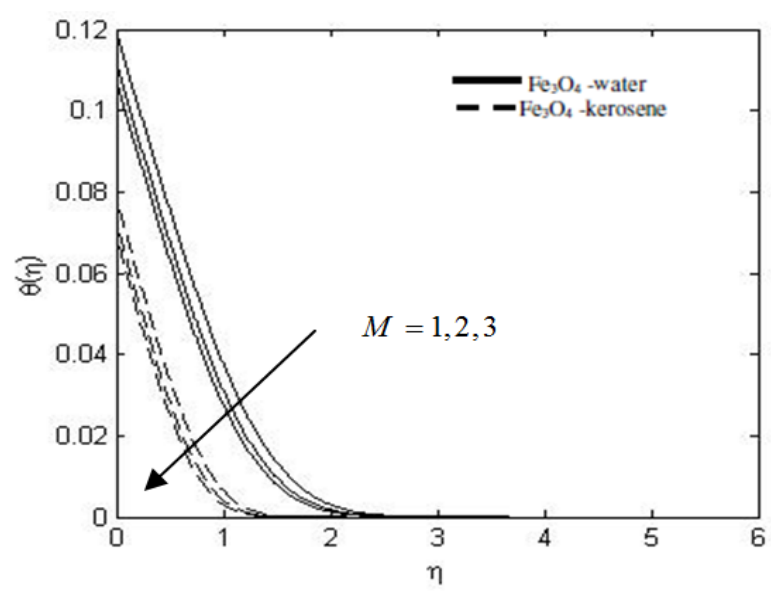

Fig. 5 Temperature Profile for increasing of Magnetic Field, $M$ for $\alpha=\pi / 2, \phi=0.1, G r_{x}=0.1, B i_{x}=0.1$

Fig. 6 and 7 illustrate the influence of volume fraction on ferroparticles on velocity and temperature profiles for both $\mathrm{Fe}_{3} \mathrm{O}_{4}$-water and $\mathrm{Fe}_{3} \mathrm{O}_{4}$-kerosene ferrofluids. It is observed, increasing the volume fraction of ferroparticles did not produce any major effect on momentum boundary layer thickness while an increase in the volume fraction causes a general increase in the plate surface temperature and thermal boundary layer.

The influence of the local Grashof number, $G r_{x}$ on the velocity and temperature are shown in Fig. 8 and 9. Increase in buoyancy forces makes the viscosity to reduce and hence the momentum boundary layer decreases continuously. Thus the fluid velocity increases (Fig. 7). As the viscosity reduces, the fluid get diluted which gives a rise to the temperature due to an increase in thermal boundary layer (Fig. 8).

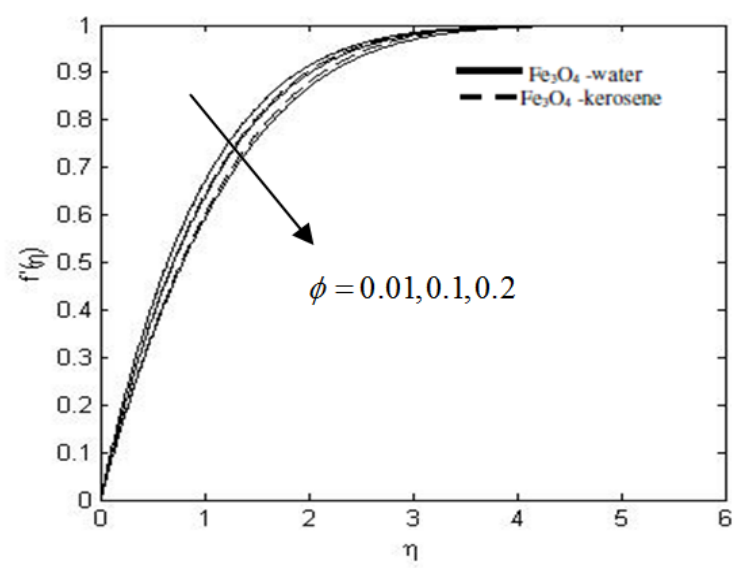

Fig. 6 Velocity Profile for increasing of Volume Fraction, $\phi$ for $\alpha=\pi / 2, M=1, G r_{x}=0.1, B i_{x}=0.1$.

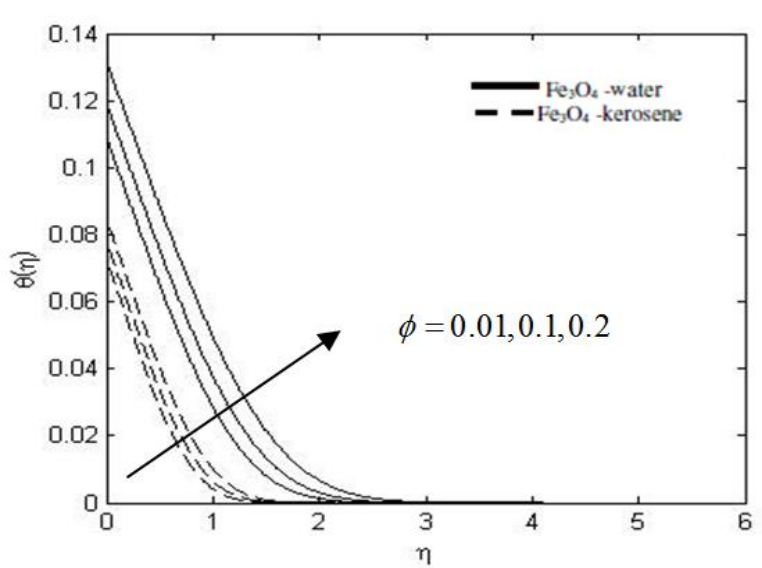

Fig. 7 Temperature Profile for increasing of Volume Fraction, $\phi$ for $\alpha=\pi / 2, M=1, G r_{x}=0.1, B i_{x}=0.1$.

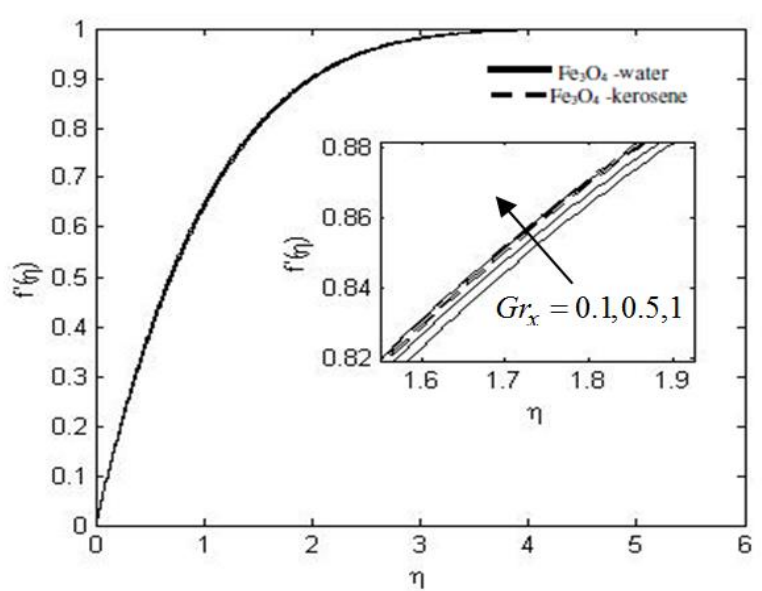

Fig 8 Velocity Profile for increasing of Grashof Number, $G r_{x}$ for $\alpha=\pi / 2, M=1, \phi=0.1, B i_{x}=0.1$.

The effect of local Biot number on velocity and temperature are presented in Fig. 9 and 10. Based on Fig. 10, it can be noticed, ferrofluid temperature increases with increase in the value of $B i_{x}$, leading to an increase in thermal boundary layer thickness. This can be attributed to the increasing effect of Biot number at the plate surface due to the hot fluid at the left surface of the plate.

Tables 3 and 4 displays the influence of non-dimensional governing parameters on local skin friction and local Nusselt number for $\mathrm{Fe}_{3} \mathrm{O}_{4}$-water and $\mathrm{Fe}_{3} \mathrm{O}_{4}$-kerosene ferrofluid respectively. It is important to note that local the local skin friction together with local Nusselt number at plate surface increases with increasing in aligned angle, magnetic field parameter, volume fraction of ferroparticle, Grashof Number and Biot number.

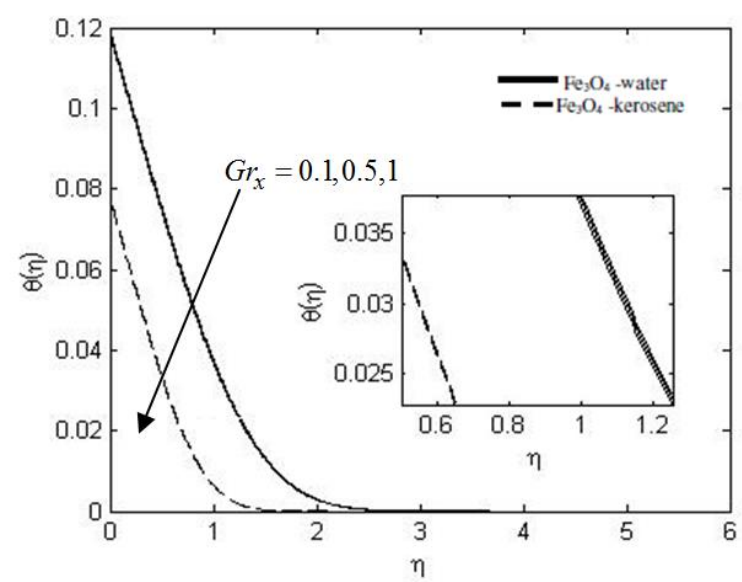

Fig. 9 Temperature Profile for increasing of Grashof Number, $G r_{x}$ for $\alpha=\pi / 2, M=1, \phi=0.1, B i_{x}=0.1$. 


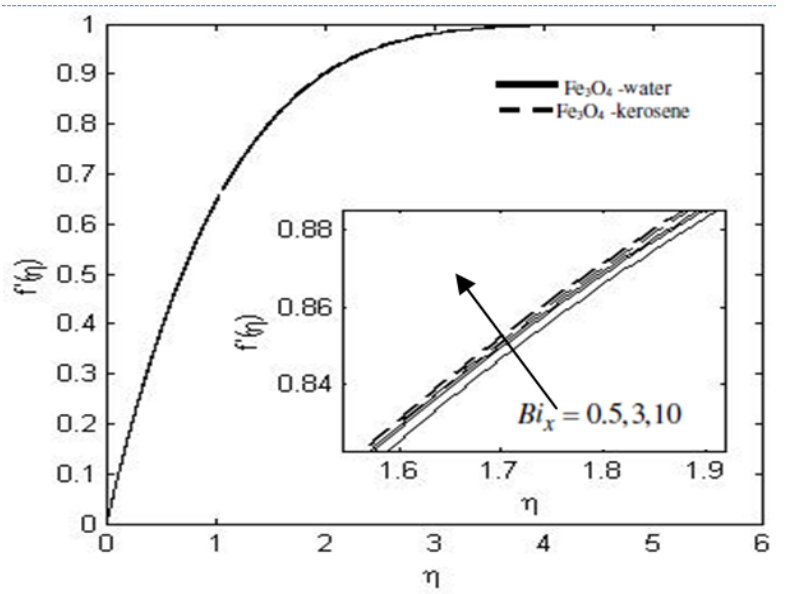

Fig. 10 Velocity Profile for increasing of Biot Number, $B i_{x}$ for $\alpha=\pi / 2, M=1, \phi=0.1, G r_{x}=0.1$.

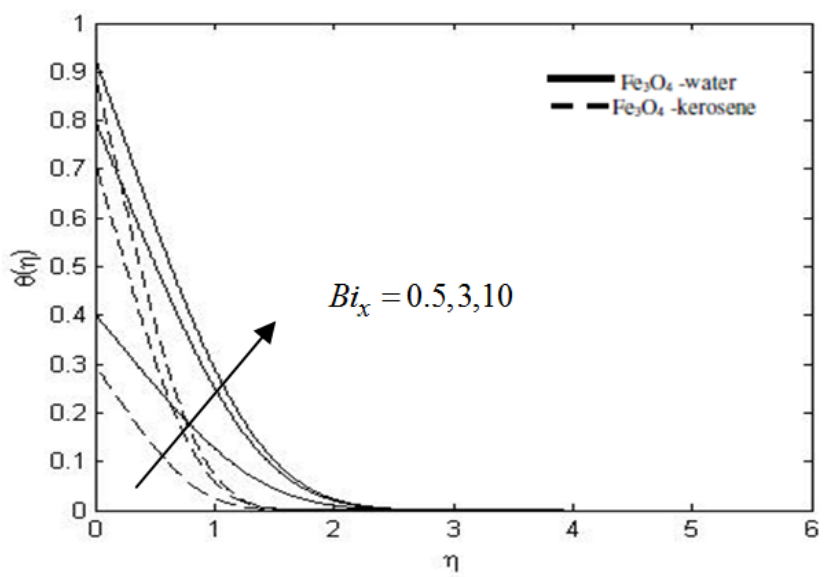

Fig. 11 Temperature Profile for increasing of Biot Number, $B i_{x}$ for $\alpha=\pi / 2, M=1, \phi=0.1, G r_{x}=0.1$.

TABLE 3 Variation in skin friction coefficient and Nusselt number for $\mathrm{Fe}_{3} \mathrm{O}_{4}$-water ferrofluids at different non-dimenesional parameters.

\begin{tabular}{ccccccc}
\hline$\alpha$ & $\phi$ & $M$ & $G r_{x}$ & $B i_{x}$ & $C_{f}\left(\mathrm{Re}_{x}\right)^{\frac{1}{2}}$ & $N u_{x}\left(\mathrm{Re}_{x}\right)^{-\frac{1}{2}}$ \\
\hline $0^{\circ}$ & 0.1 & 1 & 0.1 & 0.1 & 0.463581 & 0.106026 \\
$45^{\circ}$ & 0.1 & 1 & 0.1 & 0.1 & 0.917669 & 0.108429 \\
$70^{\circ}$ & 0.1 & 1 & 0.1 & 0.1 & 1.155081 & 0.109186 \\
$90^{\circ}$ & 0.01 & 1 & 0.1 & 0.1 & 1.064095 & 0.091099 \\
$90^{\circ}$ & 0.05 & 1 & 0.1 & 0.1 & 1.128664 & 0.098944 \\
$90^{\circ}$ & 0.1 & 1 & 0.1 & 0.1 & 1.218677 & 0.109356 \\
$90^{\circ}$ & 0.15 & 1 & 0.1 & 0.1 & 1.320869 & 0.120507 \\
$90^{\circ}$ & 0.2 & 1 & 0.1 & 0.1 & 1.437724 & 0.132480 \\
$90^{\circ}$ & 0.1 & 1 & 0.1 & 0.1 & 1.218677 & 0.109356 \\
$90^{\circ}$ & 0.1 & 2 & 0.1 & 0.1 & 1.667560 & 0.110301 \\
$90^{\circ}$ & 0.1 & 3 & 0.1 & 0.1 & 2.019862 & 0.110831 \\
$90^{\circ}$ & 0.1 & 1 & 0.1 & 0.1 & 1.218677 & 0.109356 \\
$90^{\circ}$ & 0.1 & 1 & 0.5 & 0.1 & 1.241102 & 0.109409 \\
$90^{\circ}$ & 0.1 & 1 & 1.0 & 0.1 & 1.268753 & 0.109474 \\
$90^{\circ}$ & 0.1 & 1 & 0.1 & 0.1 & 1.218677 & 0.109356 \\
$90^{\circ}$ & 0.1 & 1 & 0.1 & 3.0 & 1.250853 & 0.739192 \\
$90^{\circ}$ & 0.1 & 1 & 0.1 & 10 & 1.256922 & 0.859313 \\
\hline
\end{tabular}

TABLE 4 Variation in skin friction coefficient and Nusselt number for $\mathrm{Fe}_{3} \mathrm{O}_{4}$-kerosene ferrofluids at different non-dimenesional parameters.

\begin{tabular}{ccccccc}
\hline$\alpha$ & $\phi$ & $M$ & $G r_{x}$ & $B i_{x}$ & $C_{f}\left(\mathrm{Re}_{x}\right)^{\frac{1}{2}}$ & $N u_{x}\left(\mathrm{Re}_{x}\right)^{-\frac{1}{2}}$ \\
\hline $0^{\circ}$ & 0.1 & 1 & 0.1 & 0.1 & 0.479399 & 0.117838 \\
$45^{\circ}$ & 0.1 & 1 & 0.1 & 0.1 & 0.924532 & 0.119752 \\
$70^{\circ}$ & 0.1 & 1 & 0.1 & 0.1 & 1.160051 & 0.120359 \\
$90^{\circ}$ & 0.01 & 1 & 0.1 & 0.1 & 1.062258 & 0.095316 \\
$90^{\circ}$ & 0.05 & 1 & 0.1 & 0.1 & 1.129485 & 0.105992 \\
$90^{\circ}$ & 0.1 & 1 & 0.1 & 0.1 & 1.223280 & 0.120496 \\
$90^{\circ}$ & 0.15 & 1 & 0.1 & 0.1 & 1.329834 & 0.136475 \\
$90^{\circ}$ & 0.2 & 1 & 0.1 & 0.1 & 1.451732 & 0.154165 \\
$90^{\circ}$ & 0.1 & 1 & 0.1 & 0.1 & 1.223280 & 0.120496 \\
$90^{\circ}$ & 0.1 & 2 & 0.1 & 0.1 & 1.670501 & 0.121261 \\
$90^{\circ}$ & 0.1 & 3 & 0.1 & 0.1 & 2.022117 & 0.121693 \\
$90^{\circ}$ & 0.1 & 1 & 0.1 & 0.1 & 1.223280 & 0.120496 \\
$90^{\circ}$ & 0.1 & 1 & 0.5 & 0.1 & 1.233697 & 0.120514 \\
$90^{\circ}$ & 0.1 & 1 & 1.0 & 0.1 & 1.246631 & 0.120536 \\
$90^{\circ}$ & 0.1 & 1 & 0.1 & 0.1 & 1.223280 & 0.120496 \\
$90^{\circ}$ & 0.1 & 1 & 0.1 & 3.0 & 1.244566 & 1.108775 \\
$90^{\circ}$ & 0.1 & 1 & 0.1 & 10 & 1.250437 & 1.383637 \\
\hline
\end{tabular}

\section{CONCLUSION}

In the present paper, the combined influence MHD, natural convection and convective surface boundary condition on the boundary layer flow involving two types of base ferrofluid (water and kerosene base) containing magnetite $\left(\mathrm{Fe}_{3} \mathrm{O}_{4}\right)$ as ferroparticle over a fixed vertical flat plate. Based on the obtained results, the following conclusion can be summarized:

i) It is found that $\mathrm{Fe}_{3} \mathrm{O}_{4}$-kerosene ferrofluid proved to have the highest cooling performance for this vertical plate problem compare to $\mathrm{Fe}_{3} \mathrm{O}_{4}$ - water.

ii) The velocity of both ferrofluid increases with an increase in inclined angle, magnetic field parameter, local Grashof number and local Biot number where as it decreases with an increase in volume fraction.

iii) The temperature of the fluid decreases with an increase in inclined angle, magnetic field parameter, local Grashof number where as it increases with an increase in volume fraction and local Biot number.

iv) The Nusselt and local skin friction coefficient increases with an increase in aligned angle, magnetic field parameter, volume fraction of ferroparticle, Grashof Number and Biot number.

\section{ACKNOWLEDGEMENT}

The authors would like to acknowledge Ministry of Higher Education (MOHE) and Research Management Centre-UTM for the financial support through vote numbers 4F713, 4F538 and 06H67 for this research.

\section{REFERENCES}

[1] Choi, S. U. and Eastman, J. A. U.S. Patent 6,221,275. 2001. Enhanced heat transfer using nanofluids.

[2] Li, Y., Tung, S., Schneider, E. and Xi, S. 2009. A review on development of nanofluid preparation and characterization. Powder Technol. 196(2), 89-101. 
[3] Buongiorno, J., Venerus, D. C., Prabhat, N., McKrell, T., Townsend, J., Christianson, R., ..., Zhou, S. -Q. 2009. A benchmark study on the thermal conductivity of nanofluids. J. Appl. Phys. 106(9), 094312.

[4] Godson, L., Raja, B., Lal, D. M. and Wongwises, S. 2010. Enhancement of heat transfer using nanofluids-An overview. Renew. Sust. Energ. Rev. 14(2), 629-641.

[5] Ghadimi, A., Saidur, R. and Metselaar, H. S. C. 2011. A review of nanofluid stability properties and characterization in stationary conditions. Int. J. Heat Mass Tran. 54(17), 4051-4068.

[6] Blasius, H. 1910. Funktionentheoretische methoden in der hydrodynamik. Z. Math. Phys. 58, 90-110.

[7] Makinde, O. D. and Olanrewaju, P. O. 2010. Buoyancy effects on thermal boundary layer over a vertical plate with a convective surface boundary condition. J. Fluid Eng.-T. Asme. 132(4), 044502.

[8] Aziz, A. 2009. A similarity solution for laminar thermal boundary layer over a flat plate with a convective surface boundary condition. Commun. Nonlinear Sci. 14(4), 1064-1068.

[9] Nsofor, E. C. 2008. Recent patents on nanofluids (nanoparticles in liquids) heat transfer. Recent Pat. Mech. Eng. 1(3), 190-197.

[10] Wang, X. Q. and Mujumdar, A. S. 2008. A review on nanofluids-part I: theoretical and numerical investigations. Braz. J. Chem. Eng. 25(4), 613630

[11] Sarkar, J. 2011. A critical review on convective heat transfer correlations of nanofluids. Renew. Sust. Energ. Rev. 15(6), 3271-3277.

[12] Kamyar, A., Saidur, R. and Hasanuzzaman, M. 2012. Application of computational fluid dynamics (CFD) for nanofluids. Int. J. Heat Mass Tran. 55(15). 4104-4115.
[13] Makinde, O. D. 2011. Similarity solution for natural convection from a moving vertical plate with internal heat generation and a convective boundary condition. Therm. Sci. 15(Suppl. 1), 137-143.

[14] Olanrewaju, P. O., Arulogun, O. T. and Adebimpe, K. 2012. Internal heat generation effect on thermal boundary layer with a convective surface boundary condition. Am. J. Fluid Dyn. 2(1), 1-4.

[15] Khan, W. A., Khan, Z. H. and Haq, R. U. 2015. Flow and heat transfer of ferrofluids over a flat plate with uniform heat flux. Eur. Phys. J. Plus. 130(4), 86.

[16] Tiwari, R. K. and Das, M. K. 2007. Heat transfer augmentation in a twosided lid-driven differentially heated square cavity utilizing nanofluids. Int. J. Heat Mass Tran. 50(9), 2002-2018.

[17] Oztop, H. F. and Abu-Nada, E. 2008. Numerical study of natural convection in partially heated rectangular enclosures filled with nanofluids. Int. J. Heat Fluid Fl. 29(5), 1326-1336.

[18] Brinkman, H. C. 1952. The viscosity of concentrated suspensions and solutions. J. Chem Phys. 20(4), 571-571.

[19] Mojumder, S., Saha, S., Saha, S. and Mamun, M. A. H. 2015. Effect of magnetic field on natural convection in a C-shaped cavity filled with ferrofluid. Procedia Engineer. 105, 96-104.

[20] Sheikholeslami, M. and Rashidi, M. M., 2015. Effect of space dependent magnetic field on free convection of $\mathrm{Fe}_{3} \mathrm{O}_{4}$-water nanofluid. J. Taiwan Inst. Chem. E. 56, 6-15. 